\title{
Marcin Lewinski: Internet Political Discussion Forums as an Argumentative Activity Type. A Pragma-dialectical Analysis of Online Forms of Strategic Manoeuvring in Reacting Critically
}

\author{
Dissertation University of Amsterdam, SicSat, Amsterdam, 2010
}

\author{
Paul van den Hoven
}

Published online: 20 January 2011

(C) The Author(s) 2011. This article is published with open access at Springerlink.com

A pragma-dialectical analysis departs from an idealized model of a well-organized, fully explicit argumentative discussion. Some argumentative activity types come closer to this ideal than others. It is useful and important to apply the ideal model to reconstruct relatively well-organized and explicit practices as is done for example in argumentation in legal proceedings. But it is great fun to explore what happens when you confront the seemingly anarchistic and chaotic practices of Internet political forum discussions with such a model, at least when you do this with the subtlety and intelligence of Marcin Lewinski. He reports his findings in a wellwritten, very interesting study.

The first four chapters of this doctoral dissertation are somewhat perfunctory, working towards an introduction of the concepts of a critical discussion (shared knowledge for the readers of this journal), strategic maneuvering (a more recent, but also well-known concept) and argumentative activity type in the pragma-dialectical theory (relatively new). "[B]y manoeuvring strategically arguers try to make an advantageous use of the many options open to them at various junctures of a reasonable dialectical discussion" (p. 55). Van Eemeren \& Houtlosser characterize argumentative activity types as "conventionalized entities that can be distinguished by 'external' empirical observations of the communicative practices in the various domains [...] of discourse". Lewinski states that "pragma-dialectical activity types are empirically recognisable types of communicative practices approached from the perspective of a normative model" (p. 60) ${ }^{1}$.

Chapter 5 characterizes Internet discussion forums as a technology for informal political deliberation. On the basis of a technological and institutional analysis of

\footnotetext{
1 The most recent book by Frans van Eemeren, Strategic maneuvering in argumentative discourse: Extending the pragma-dialectical theory of argumentation, had not been published yet at the moment of completion of Lewinski's study but it was available to him as a manuscript.
}

P. van den Hoven $(\bowtie)$

Utrecht University, Utrecht, The Netherlands

e-mail: p.vandenhoven@uu.nl 
Internet discussion fora Lewinski concludes that "online fora function as vehicles for informal political discussion that can (exclusively) realise the goal of critical opinion-formation" (p.79). The important difference with institutionalized forms of deliberation is that the participants do not participate in decisions about the course of action to be taken. This however does not make them futile discussions for the sake of discussing, Lewinski argues from a pragma-dialectical perspective. "As long as standpoints and arguments are advanced and tested in a reasonable way, highly valued critical exchanges that may more or less directly increase the quality of 'deliberative opinion' are under way' (p. 78).

In Chap. 6, Internet discussions are analyzed as an argumentative activity type, while in Chap. 7 specific constraints on critical reactions are evaluated on the impact they may have on strategic maneuvering. Online political forum discussions take place among many pseudonymous participants, who may team up and who can join in and withdraw at any moment. This means that a discussant presents his or her arguments to "a multilayered, fluid, mixed and largely unknown audience" (p. 133), arguments that will however be promptly challenged publicly. "Because of the lack of fixed starting points regarding premises and argument schemes, the antagonist in online discussions may extensively exploit the topical potential by coming up with as many critical reactions as possible" (p. 136). The presentational devices give access to the entire history of the discussion in the form of literal utterances and their relations, which supports the opportunity for the antagonistic crowd to follow all potential dialectical routes. This, according to Lewinski, often leads to a thorough testing of the protagonist's argumentation.

In Chap. 8. Lewinski discovers four patterns of strategic maneuvering apparent in the reactions of the antagonist. The first one is "that the basic, 'entry level' onlinespecific mode of attacking the propositional content of argumentation is to request the protagonist of a standpoint to provide a link supporting his position" (p. 141). "Provision of links or citations backing one's arguments [...] gains the status of a convention internalised and acknowledged by Internet arguers" (p. 144), which even leads to meta-discussions in which protagonists appeal to this convention. I got an informal but significant confirmation of Lewinski's observation from a $\mathrm{PhD}$ student at Peking University. A regular participant on international political fora, he uttered his frustration at having been confronted many times with the criticism that he did not add sufficient relevant links (to support his argumentation) and not being able to respond to these reactions, due to the fact that the Chinese Internet censorship made it impossible or unadvisable for him to refer to the relevant sites. He assured me that he shared this experience with many of his Chinese friends. The second pattern observed by Lewinski is that different arguers in their role of collective antagonist explore criticisms that together show a certain order. Several different individuals do indeed act as a team in filling in a role in a dialectical profile. The third pattern is that the (collective) antagonist criticizes as much as possible. "Online antagonists can simply make the most of the opportunities to uninhibitedly criticize the opinions they find weakly justified, thus fully exploring the topical potential for reacting critically". (p. 165). Lewinski seems to evaluate this as being a quality of the way of opinion formation. The fourth pattern, illustrated by Lewinski with several examples, is that a reproach of topical 
irrelevance is presented as a (weak) justification to disqualify a critical response. Topical (ir)relevance, he shows, is not equivalent to a specific type of argumentative (ir)relevance. The requirement to stick strictly to the topic is a typical convention of discussion fora. However, according to Lewinski, it can be reconstructed as a rather undetermined all-in-one criticism of the justificatory force of argumentation.

Lewinski's study shows convincingly that confronting the seemingly anarchistic realm of political online discussions with the pragma-dialectical model is indeed productive and provides new insights. There is order and even traces of argumentative reasonableness immediately below the seemingly chaotic surface of this activity type. Basic pragma-dialectic notions do apply and suffice to relate this social practice as an argumentative activity type to other argumentative activity types. This is an important insight. People who freely and without any direct institutionalized interest engage in online discussions still to some extent pattern themselves on general principles of argumentative reasonableness as modeled in the pragma-dialectical theory.

But obviously there are risks to his methodology. The lines in italics above illustrate how Lewinski attempts to fit this practice into the normative model and how this may lead to overrating the rationality and functionality. Certainly, the examples Lewinski gives show interesting and elaborated argumentative exchanges. But do online political discussions indeed reveal more arguments for and againstmore often than merely incidentally - than those that are taken into account by decision makers in their institutionalized debates? Lewinski does not give any empirical evidence for this claim. What the impact of these processes of opinion formation is on the actual decision making processes remains an object of speculation. It seems difficult for Lewinski-and maybe for the theory as it is structured now-to accept the possibility that a practice reflects some rules and principles of the pragma-dialectical theory without a clear relation with a concept of practical reasonableness.

Lewinski in Chap. 6 shows a strong eagerness to discover counterparts of pragma-dialectical rules in the Google 'terms of service' and its set of forum rules. Some of these rules "may be seen as real-life specifications" (p. 93) of a pragmadialectical rule. He remains careful: "It is not difficult to see how these rules correspond to argumentative norms, even if this correspondence is purely coincidental" (p. 95). Still the exercise is an invitation to confuse minimal social courtesy (netiquette) with dialectical goal-oriented argumentative reasonableness. Thus, Lewinski relates a forum rule that forbids posts that are made merely to insult to the pragma-dialectical rule that disqualifies an argumentum ad baculum or ad hominem. The latter rule is motivated from a clear argumentative goal, i.e., to optimally carry forward the process of reasonable conflict resolution. But why would this be a goal in online discussions? Online discussions do not have such an articulated goal and are rightly characterized by Lewinski as not constrained by time limits.

Lewinski's attempt to dig up the layers of reasonableness is exciting, fun and theoretically important. What is perhaps inherent in this enterprise is that we tend to lose sight of what online discussions also are: an often rude, abusive game. The image that we get from the examples and from the overall line of approach of the 
analyses contrasts with impression one may also get when roaming around on platforms that invite serious response. When the Los Angeles Times invites comments on the question whether image should influence a jury's decision, a question inspired by the case of a gang member who had been kicked in the head by a police officer and whose attorney advised him to undergo a serious makeover before appearing in court to argue his legal claim against the city, these comments, while quite outspoken, start out reasonable [I did not correct any errors].

1. I think if you want to commit crimes, join a street gang and run from the police, you are going to get what you deserve. Quit waisting our tax dollars. This state is so screwed up. I give it another year before this ship sinks. There are more people voting for anything that they can get for free than there are voters who actually contribute. The tipping point has already occured. Atlas will Shrug....

2. The officers screwed up and should have not kicked the guy when he was already down on the ground surrendering. The gang member was a wuss when he gave up and the cop was a cowboy and now the citizens of El Monte will be paying for his bad judgment.

3. It's nothing other then disgusting that this SCUM gang member is trying to get $\$ 5,000,000$. He deserves to be executed publicly for his disgusting lifestyle. This case should be thrown out immediately. I am so sick of these ACLU B.S. cases.

In his last analytical Chap. 9, Lewinski gives a detailed and theoretically interesting analysis of the straw man fallacy in reacting critically in Internet fora. The theoretical subtleties of his analysis of the charity principle (p. 192-210) are important for the general theory. Applied to the actual practice of Internet discussions one should not lose sight of the way comment 4 reformulates the former three. Practice seems less subtle than Lewinski's analyses.

4. Love the comments. A doomsayer, a policeman with a conscious and an angry "taxpayer" that more than likely never paid a dime to the system. Guilty until proven innocent, yeah? God Bless America.

Lewinski's focus on the elements that can be reconstructed as part of a more or less reasonable argumentation should not make us forget the 'stylistics' of the language used as in 4, nor the fact that the argumentative parts often have to be extracted from series of responses as the following two.

5. I wish there would have been goalposts and two referees and the officer would have kicked a fieldgoal with this guys head. It's Good !!!

6. His "before" look is practically a plea for getting his head kicked. What a moron!

If one wants to formulate a critical point about this rich study then it would have to be that Lewinski does not succeed yet in shedding light on the relation between these two seemingly incompatible faces of this intriguing social and-thanks to him now also-clearly argumentative practice. 
Open Access This article is distributed under the terms of the Creative Commons Attribution Noncommercial License which permits any noncommercial use, distribution, and reproduction in any medium, provided the original author(s) and source are credited. 